\title{
Effect of amino acid-functionalized multi-walled carbon nanotubes on the properties of dopamine-based poly(amide-imide) composites: An experimental study
}

\author{
SHADPOUR MALLAKPOUR ${ }^{\mathrm{a}, \mathrm{b}, \mathrm{c}, *}$ and AMIN ZADEHNAZARI ${ }^{\mathrm{a}}$ \\ ${ }^{a}$ Department of Chemistry, Organic Polymer Chemistry Research Laboratory, Isfahan University of Technology, \\ Isfahan 84156-83111, I.R. Iran \\ ${ }^{b}$ Nanotechnology and Advanced Materials Institute, Isfahan University of Technology, Isfahan 84156-83111, I.R. Iran \\ ${ }^{c}$ Department of Chemistry, Centre of Excellence in Sensors and Green Chemistry, Isfahan University of Technology, \\ Isfahan 84156-83111, I.R. Iran
}

MS received 26 April 2013; revised 25 May 2013

\begin{abstract}
In a single-step, rapid microwave-assisted process, multi-walled carbon nanotubes were functionalized by $S$-valine amino acid. Formation of amino acid on nanotube surface was confirmed by Fourier transform-infrared spectroscopy, thermogravimetric analysis, X-ray diffraction, field emission scanning and transmission electron microscopy techniques. The surface-modified nanotubes showed better chemical stability in common solvents such as $N, N$-dimethylacetamide. The effects of amino acid functionalization of multiwalled carbon nanotubes on the properties of nanotube/poly(amide-imide) nanocomposites were investigated. The functionalized carbon nanotubes (5-15 wt \%) were dispersed homogeneously in the poly(amide-imide) matrix, while the structure of the polymer and the nanotubes structure were stable in the preparation process as revealed by microscopic observations. The properties of nanocomposites were characterized extensively using the aforementioned techniques. The composite films have been prepared by casting a solution of precursor polymer containing $S$-valine-functionalized carbon nanotubes into a thin film and its tensile properties were examined. The Young's modulus (elastic modulus) and tensile strength of the composite films were greatly improved by the incorporation of modified nanotubes.
\end{abstract}

Keywords. Multi-walled carbon nanotubes; amino acids; nanocomposite; mechanical properties.

\section{Introduction}

Nanocomposites (NCs) are among the most diverse materials owing to their ability to incorporate a number of different filler materials. Due to tremendous improvement observed in the properties of the NCs, research interest in this area has grown exponentially in recent years (Friedrich et al 2005). In designing better NCs for advanced technological applications, some of the major challenges are understanding the structure-property relationships, interaction and integrity of the two components at the interface and the role of nanofillers in enhancing the properties of the resulting material. The addition of these filler materials can reduce cost, alter mechanical properties, reduce mould shrinkage, control viscosity and alter surface properties. These properties illustrated by NCs allow them to be used for a wide variety of manufacturing applications (Ohno et al 2008; Grady 2011). The ideal reinforcement material for a polymer, which is

*Author for correspondence (mallak@cc.iut.ac.ir, mallakpour84@ alumni.ufl.edu, mallak777@yahoo.com) characterized as a very ductile material, is a highly rigid material with a large elastic modulus. The most commonly used filler materials for polymer matrix NCs are carbon nanotubes (CNTs). Individually, CNTs have extreme mechanical, electrical and thermal properties. Incorporation of CNTs into the composite matrices leads to new or modified property enhancements greater than that achievable using conventional fillers or polymer blends (Agarwal et al 2008). A commonly used method for preparing nanotube/polymer composites is mixing nanotube dispersions with solutions of the polymer and then evapourating the solvents in a controlled way (Wong et al 2003; Allen et al 2013; Song et al 2013). The key issues for fabricating technically interesting CNT/polymer NCs are the complete and well-organized dispersion of the CNTs into a polymer matrix, as well as the control of the properties of the filler-matrix interface (Ma et al 2010). The simple mixing method of CNTs and polymer molecules has the disadvantage that the dispersion of CNTs in the composites is a weak static equilibrium: once the material temperature rises, molecular heat movement intensifies, and CNT dispersion status is destroyed, leading to recoagulation. The resultant improvement in mechanical strength 
and thermal stability is therefore limited (Grady 2010). A chemical modification to CNTs, so that their surfaces carry an electrostatic charge or form functional groups to participate in a reaction (e.g. $-\mathrm{OH},-\mathrm{NH}_{2}$ or $-\mathrm{COOH}$ ) and polymerize with monomers to change the surface structure and status would allow them to be mixed homogeneously with a matrix, thus improving the physical properties of the matrix (Bal and Samal 2007; Scheibe et al 2010; Mohanapriya et al 2012). However, if well dispersed, the potential filler-matrix interface area is huge, and a perfect control of the interfacial interaction is crucial for obtaining optimal properties.

Polyimides (PIs) rank among the most heat-resistant polymers on the basis of their excellent properties, i.e. considerably high glass transition temperature $\left(T_{\mathrm{g}}\right)$, excellent resistance to chemicals, highly stable electrical insulation performance, relatively low dielectric constants and good mechanical properties (Liaw et al 2012). Recently, higher-performance functional PIs are in great demand for use in some advanced electronic devices as flexible substrates and dielectric interlayers (Park et al 2011; Tang et al 2011). Nevertheless, they have some major shortcomings. Unless carefully designed, they have inferior solubility in most organic solvents and processing difficulties due to high melting points and $T_{\mathrm{g}} \mathrm{s}$. To overcome these shortcomings, various noteworthy attempts have been made to modify the rigid-chain structure of such polymers by the incorporation of flexible linkages such as amide, ether, ester and sufide linkages (Zhang et al 2010; Laurentia et al 2013; Rajesh et al 2013). Incidentally, poly(amide-imide)s (PAIs) possess the desirable characteristics of the polyamides and PIs such as high thermal stability and good mechanical properties, as well as easy processability. So, a wide range of aromatic PAIs have been investigated as high-performance materials for applications, such as mouldings, wire-coating enamels, composite matrices, fibres, films, foams, and high-temperature adhesives (Murray 2008; Mohan and Ahmad 2011; Setiawan et al 2012; Thiruvasagam and Vijayan 2012).

Recently, the synthesis, manufacturing and potential application of CNT/polymer NCs have attracted attention and interest from academics and industry, but a few studies concerned with the fabrication of multi-walled CNT (MWCNT)/PAI composites have been carried out (Lee et al 2010a; Mallakpour and Zadehnazari 2012a, b, c; 2013a, b). One of the main limitations of CNTs is the lack of solubility in solvents. This paper aims to study and tailor a simple, novel and green approach to covalently functionalize MWCNTs by using microwave irradiation and to present evidences for the covalent attachment between MWCNTs and the $S$-valine (Val) amino acid. Then, we used a simple ultrasonically assisted solution blending procedure to prepare effectively stable MWCNTs-Val dispersion, with the aid of an amino acid-based PAI. The introduction of several functional groups as well as dopamine moiety and amino acid bulky substituents resulted in increased chain packing distances and decreased intermolecular interactions, leading to better interaction of the polymer chains with MWCNTs-Val and better dispersion of MWCNTs-Val in the polymer matrix.

\section{Experimental}

\subsection{Materials}

A carboxyl-modified MWCNT (diameter 8-15 nm, length $\sim 50 \mu \mathrm{m}$, carboxyl content $2.56 \mathrm{wt} \%$, and purity $>95 \mathrm{wt} \%$ ), manufactured by a thermal chemical vapour deposition process, was purchased from Neutrino Co. (Iran). Other chemicals used in this study were obtained commercially from Fluka Chemical Co. (Switzerland), Aldrich Chemical Co. (Milwaukee, WI) and Merck Chemical Co. (Germany). Dopamine hydrochloride (3-hydroxytyraminium chloride), 3,5-dinitrobenzoylchloride, trimellitic anhydride (TMA), $S$-valine amino acid, glacial acetic acid, propylene oxide, tetrabutylammonium bromide (TBAB) and triphenyl phosphite (TPP) were used as received without further purification. Propylene oxide was used as acid scavenger. Hydrazine monohydrate and $10 \%$ palladium on activated carbon were used as received. $N, N$-dimethylformamide (DMF) $\left(d=0.94 \mathrm{~g} \mathrm{~cm}^{-3}\right.$ at $\left.20^{\circ} \mathrm{C}\right)$, and $N, N$ dimethylacetamide (DMAc) $\left(d=0.94 \mathrm{~g} \mathrm{~cm}^{-3}\right.$ at $\left.20{ }^{\circ} \mathrm{C}\right)$ as solvents were distilled over barium oxide under reduced pressure before use. Other reagents were used without further purification.

\subsection{Instrumentation}

Functionalization of MWCNTs and synthesis of polymer were carried out in a Samsung microwave oven (2450 MHz, 900 W) (Seoul, South Korea). Melting points of the monomers were measured on a melting-point apparatus (Gallenhamp, Cambridge, UK) without correction. ${ }^{1} \mathrm{H}$ and ${ }^{13} \mathrm{C}$ nuclear magnetic resonance (NMR) spectra were recorded on a Bruker (Rheinstetten, Germany) Avance 500 instrument at room temperature in dimethylsulphoxide- $d_{6}$ (DMSO- $d_{6}$ ). Multiplicities of proton resonance were designated as singlet $(s)$, doublet $(d)$ and multiplet $(m) .{ }^{13} \mathrm{C}$ spectrum was broadband proton decoupled. The chemical shifts were reported in ppm with respect to the references and stated relative to external tetramethylsilane (TMS) for ${ }^{1} \mathrm{H}$ and ${ }^{13} \mathrm{C}$ NMR. Fourier transform-infrared (FT-IR) spectra of the samples were recorded with a Jasco-680 (Tokyo, Japan) spectrometer (taken in potassium bromide $(\mathrm{KBr})$ ) at a resolution of $4 \mathrm{~cm}^{-1}$. They were scanned at wavenumber range of $400-$ $4000 \mathrm{~cm}^{-1}$. Band intensities were assigned as weak $(w)$, medium $(m)$, strong $(s)$ and broad $(b r)$. Vibration bands were reported as wavenumber $\left(\mathrm{cm}^{-1}\right)$. Elemental analysis was performed using Elementar Analysensysteme GmbH (Hanau, Germany). Inherent viscosity was measured 

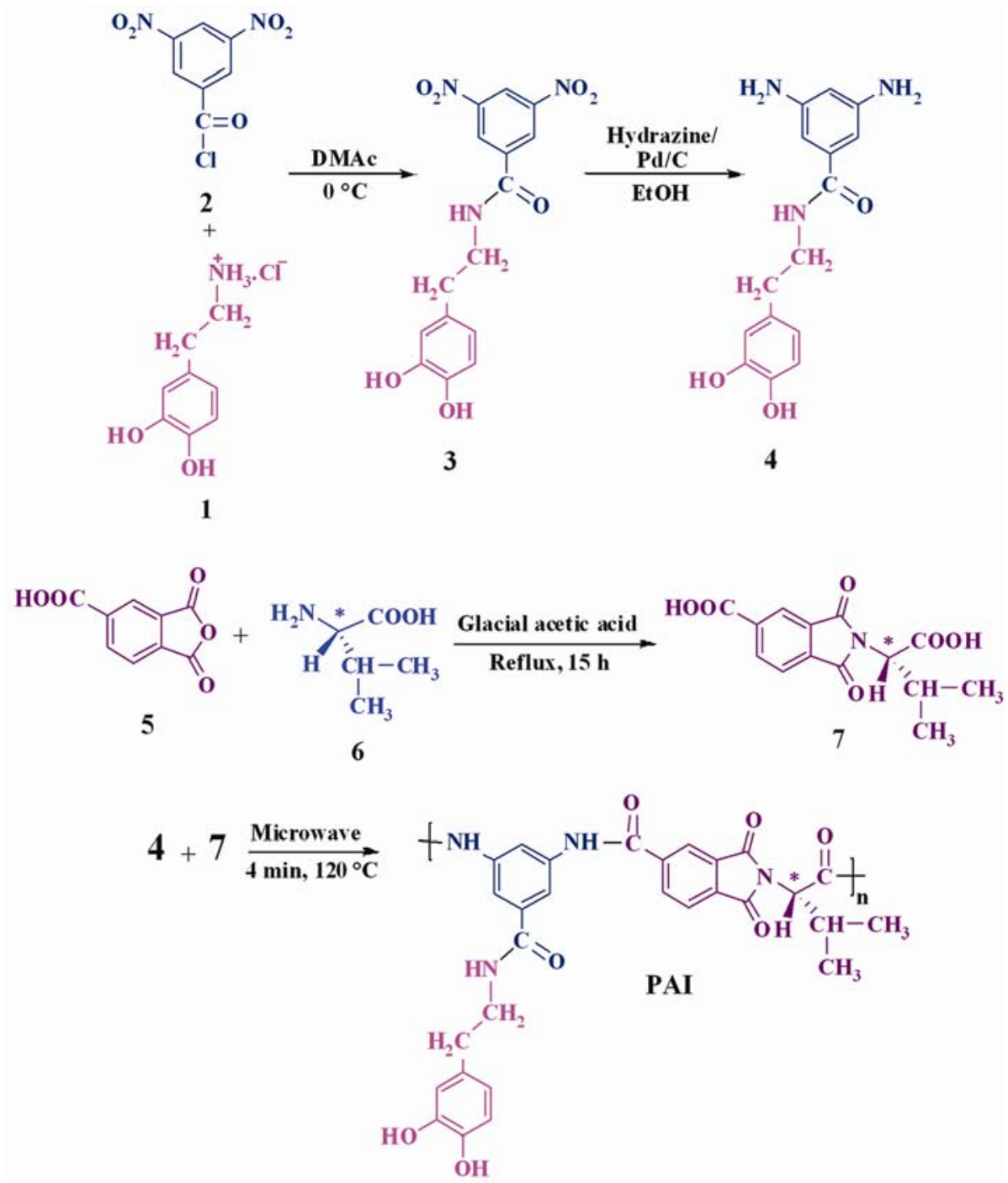

Figure 1. Synthesis of monomers and PAI.

using a Cannon Fenske Routine Viscometer (Mainz, Germany) at a concentration of $0.5 \mathrm{~g} / \mathrm{dL}$ in DMF at $25{ }^{\circ} \mathrm{C}$. Optical specific rotation was measured at the concentration of $0.5 \mathrm{~g} / \mathrm{dL}$ in DMF at $25^{\circ} \mathrm{C}$ using a quartz cell $(1 \mathrm{~cm})$ with a Jasco Polarimeter (JASCO Co. Ltd., Tokyo, Japan). Thermal stability of the MWCNTs, PAI and MWCNT/PAI NCs was evaluated by recording thermogravimetric analysis (TGA)/derivative thermogravimetric (DTG) traces (STA503 TGA, Bahr-Thermoanalyse $\mathrm{GmbH}$, Hüllhorst, Germany) in the nitrogen atmosphere (flow rate $60 \mathrm{~cm}^{3} / \mathrm{min}$ ). A heating rate of $10^{\circ} \mathrm{C} / \mathrm{min}$ and a sample size of $10 \pm 2 \mathrm{mg}$ were used in each experiment. $\mathrm{X}$-ray diffraction (XRD) was used to characterize the crystalline structure of the samples. XRD patterns were collected using a Bruker, D8ADVANCE diffractometer (Rheinstetten, Germany) with a copper target at the wave length of $\lambda \mathrm{CuK} \alpha=1.54 \AA$, a tube voltage of $40 \mathrm{kV}$ and a tube current of $35 \mathrm{~mA}$. The samples were scanned at a rate of $0.05^{\circ} / \mathrm{min}$ from 10 to $80^{\circ}$ of $2 \theta$. For XRD studies, rectangular pellets prepared by compression moulding were used. The morphology of the MWCNTs and dispersion morphology of the MWCNTs-Val on the PAI matrix were observed using field emission scanning electron microscopy (FESEM). The images were taken at $15 \mathrm{kV}$ using a HITACHI S-4160 instrument (Tokyo, Japan). Transmission electron microscopy (TEM) images were obtained using a Philips CM 120 microscope (Germany) with an accelerating voltage of $100 \mathrm{kV}$. For TEM studies, ultra-thin sections (30-80 nm) of MWCNTs-Val and the NCs were prepared using Leica Ultramicrotome. Tensile testing was performed at room temperature on a Testometric Universal Testing Machine M350/500 (Mainz, Germany), according to ASTM D 882 (standards). Tests were carried out with a cross-head speed of $12.5 \mathrm{~mm} / \mathrm{min}$ until reaching a deformation of $20 \%$ and, then, at a speed of $50 \mathrm{~mm} / \mathrm{min}$ at break. The dimensions of the test specimens were $35 \times 2 \times 0.04 \mathrm{~mm}$. Property values reported here represented an average of the results for tests 

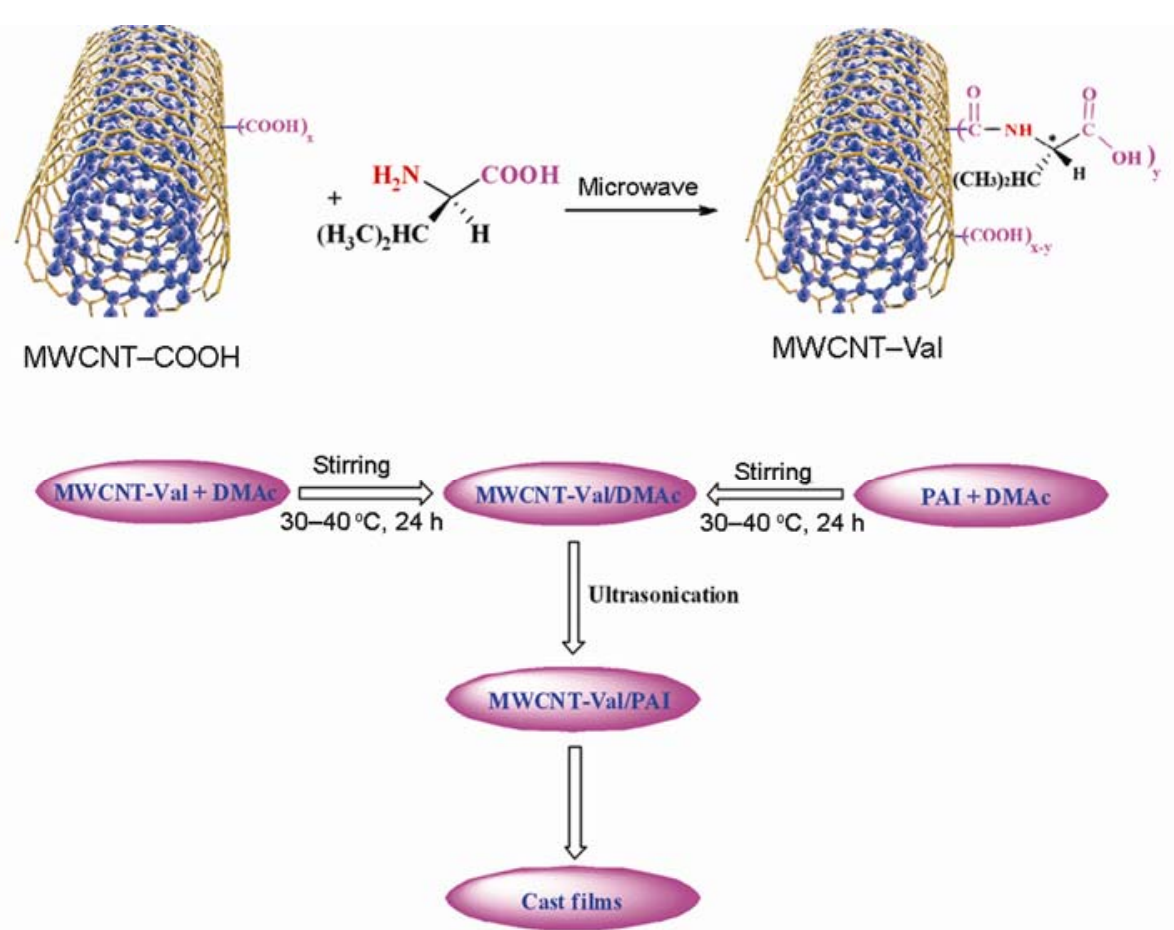

Figure 2. Schematic drawing of functionalization of MWCNTs with $S$-valine amino acid and the preparation process of MWCNT-Val/PAI NCs.

run on at least five specimens. Tensile strength, tensile modulus and strain were obtained from these measurements. Preparation of MWCNT-Val/PAI composites was carried out on a MISONIX ultrasonic XL-2000 SERIES (Raleigh, North Carolina, USA). Ultrasonic irradiation was performed with the probe of the ultrasonic horn being immersed directly into the mixture solution system with a frequency of $2 \cdot 25 \times 10^{4} \mathrm{~Hz}$ and power of $100 \mathrm{~W}$.

\subsection{Synthesis of monomers}

3,5-diamino- $N$-(3,4-dihydroxy-phenethyl)benzamide as a diamine monomer was prepared according to the reported procedure (Mallakpour et al 2011).

$\mathrm{N}$-trimellitylimido-S-valine (7) was prepared according to our previous work (Mallakpour et al 2002). The typical synthesis procedure of the diamine 4 and diacid 7 was given according to the strategy outline in figure 1 .

\subsection{Amino acid functionalization of MWCNTs}

In a typical experiment (figure 2), $S$-valine amino acid (200 mg) was mixed with DMAc $(20 \mathrm{~mL})$ for $2 \mathrm{~h}$ at $60{ }^{\circ} \mathrm{C}$. The pristine carboxylated-MWCNTs $(100 \mathrm{mg})$ and $\mathrm{NaNO}_{2}$ (100 mg) were sonicated with $20 \mathrm{~mL}$ DMAc for $2 \mathrm{~h}$ until a homogeneous suspension was obtained. The MWCNTs suspension was then poured into a porcelain dish $(50 \mathrm{~mL})$ and placed in a domestic microwave chamber. The aforementioned MWCNTs suspension was heated in a microwave up to $120^{\circ} \mathrm{C}$ for 15 min with output power of $700 \mathrm{~W}$. Then, the resulting suspension was cooled to room temperature and poured into $200 \mathrm{~mL} \mathrm{HCl}$ solution $(5 \% \mathrm{v} / \mathrm{v})$. The mixture was stirred for $30 \mathrm{~min}$ at room temperature and then decanted to remove the solvent. When the amount of solvent reached about $20 \mathrm{~mL}$, the mixture was subjected to irradiation with high-intensity ultrasound for $1 \mathrm{~h}$. The obtained homogeneous suspension was placed in an $80^{\circ} \mathrm{C}$ oven overnight to evapourate most of the solvent. The filtration products were washed more than 7 times with DMAc and water for removal of any unreacted residue amino acids, and then dried for $48 \mathrm{~h}$ at $50{ }^{\circ} \mathrm{C}$.

\subsection{Synthesis of PAI}

The one-step polycondensation reaction of equimolecular amounts of diamine 4 and diacid 7 , using molten TBAB as a reaction medium and TPP as a homogenizer, gave the PAI (figure 1). A typical reaction was carried out as follows: $0.10 \mathrm{~g}\left(3.43 \times 10^{-4} \mathrm{~mol}\right)$ of diacid monomer 7 , $0.098 \mathrm{~g}\left(3.43 \times 10^{-4} \mathrm{~mol}\right)$ of diamine 4 and $0.44 \mathrm{~g}$ of TBAB $\left(13.72 \times 10^{-4} \mathrm{~mol}\right)$ were placed in a porcelain dish and ground completely for $5 \mathrm{~min}$; then, $0.36 \mathrm{~mL}(13.72 \times$ $10^{-4} \mathrm{~mol}$ ) of TPP was added and the mixture was ground for $3 \mathrm{~min}$. The reaction mixture was irradiated in the microwave oven for $4 \mathrm{~min}$ at $100 \%$ of power level $(900 \mathrm{~W})$ (the temperature of the reaction was $120^{\circ} \mathrm{C}$ ). 
The resulting viscous solution was poured into $30 \mathrm{~mL}$ of methanol, filtered and dried at $80{ }^{\circ} \mathrm{C}$ for $6 \mathrm{~h}$ under vacuum to give $0.16 \mathrm{~g}$ (88\%) of orange powder PAI. The optical specific rotation was measured $\left([\alpha]_{\mathrm{Na}, 589}^{25}=-27.98\right)$ at a concentration of $0.5 \mathrm{~g} / \mathrm{dL}$ in DMF at $25^{\circ} \mathrm{C}$. The inherent viscosity was also measured $\left(\eta_{\text {inh }}=0.53 \mathrm{dL} / \mathrm{g}\right)$ under the same conditions.

FT-IR $\left(\mathrm{KBr}, \mathrm{cm}^{-1}\right): 3392(m, b r, \mathrm{~N}-\mathrm{H}$ and $\mathrm{O}-\mathrm{H}$ stretching), 3101 ( $w, \mathrm{C}-\mathrm{H}$ aromatic), 2962 ( $w, \mathrm{C}-\mathrm{H}$ aliphatic), 2930 ( $w, \mathrm{C}-\mathrm{H}$ aliphatic), 1777 ( $m, \mathrm{C}=\mathrm{O}$ imide, asymmetric stretching), $1719(\mathrm{~s}, \mathrm{C}=\mathrm{O}$ imide, symmetric stretching), 1648 ( $s, \mathrm{C}=\mathrm{O}$ amide, stertching), 1599 (s), 1547 (s), 1445 (s), 1376 (s, C-N-C axial stretching), 1198 ( $\mathrm{m}, \mathrm{C}-\mathrm{N}-\mathrm{C}$ transverse stretching), $1068(\mathrm{~m}), 871$ (m), $764(\mathrm{~m}), 726$ ( $\mathrm{s}, \mathrm{C}-\mathrm{N}-\mathrm{C}$ out-of-plane bending), 681 (w). ${ }^{1} \mathrm{H}-\mathrm{NMR}\left(400 \mathrm{MHz}, \mathrm{DMSO}-d_{6}, \mathrm{ppm}\right): 0.85$ (d, 3H, $\mathrm{CH}_{3}$, distorted), $1 \cdot 30-1.31\left(d, 3 \mathrm{H}, \mathrm{CH}_{3}, J=5.4 \mathrm{~Hz}\right), 1.56$ ( $m, 1 \mathrm{H}, \mathrm{C}-\mathrm{H}), 2.63\left(t, 2 \mathrm{H}, \mathrm{CH}_{2}\right.$, distorted), $3.16(t, 2 \mathrm{H}$, $\mathrm{CH}_{2}$, distorted), 4.73 (d, $1 \mathrm{H}, \mathrm{C}-\mathrm{H}$, distorted), 6.47-6.49 (d, 1H, Ar- $\mathrm{H}, J=8.40 \mathrm{~Hz}), 6.61-6.63(d, 1 \mathrm{H}, \mathrm{Ar}-\mathrm{H}$, $J=7 \cdot 2), 7 \cdot 67$ (s, 1H, Ar-H), $7.74(s, 1 \mathrm{H}, \mathrm{Ar}-\mathrm{H}), 7.94$ (s, 1H, Ar-H), 7.99 (s, 1H, Ar-H), $8.08(d, 1 \mathrm{H}$, Ar-H, distorted), 8.52 (s, 1H, Ar-H), 8.63-8.65 (d, 1H, Ar-H, distorted), 8.75 (s, 1H, N-H), 10.22 (s, 1H, O-H), $10 \cdot 31$ (s, 1H, O-H), $10 \cdot 77$ (s, 1H, N-H), $10 \cdot 84$ (s, $1 \mathrm{H}$, $\mathrm{N}-\mathrm{H})$.

Elemental analysis: calculated for $\left(\mathrm{C}_{29} \mathrm{H}_{26} \mathrm{~N}_{4} \mathrm{O}_{7}\right)_{n}$ : C, 64.20\%; H, 4.83\%; N, 10.33\%. Found: C, 64.12\%; H, $4 \cdot 62 \% ; \mathrm{N}, 10 \cdot 21 \%$.

\subsection{Preparation of the MWCNT/PAI composite films}

A two-step procedure was used to achieve homogeneously mixed MWCNT/PAI solutions with desired weight percentages of MWCNT. First, two stock solutions were prepared: PAI was dissolved and MWCNT-Val was separately dispersed in DMAc solution with stirring lasting for 1 day at $30-40{ }^{\circ} \mathrm{C}$. Then, two stock solutions were mixed to achieve the desired weight percentages of MWCNT-Val from 5 to $15 \mathrm{wt} \%$. The MWCNT-Val/PAI solution was stirred for 1 day at $30-40{ }^{\circ} \mathrm{C}$ and then, ultrasonicated in a water bath for $1 \mathrm{~h}$. To remove the DMAc solvent, MWCNT-Val/PAI solution was poured into uncovered preheated glass petri dishes and uniformly heated at $60^{\circ} \mathrm{C}$ for 1 day; then the semi-dried film was further dried in vacuum at $160{ }^{\circ} \mathrm{C}$ for $8 \mathrm{~h}$ in order to remove the residue solvent and a solid film was formed. Curly films formed after the evapouration of DMAc could be easily lifted from the glass petri dishes. Freestanding polymer films of $40 \mu \mathrm{m}$ thickness were then peeled from the glass plate and subjected to different tests. Because MWCNT is black in colour, the film containing more MWCNT looked darker: film colours varied from tan (0\% MWCNT) to light grey (5\% MWCNT) and dark black (10 and 15\% MWCNT). Uniform colour, an indication of good distribution of MWCNTs in the polymer matrix, was observed.

\section{Results and discussion}

\subsection{Monomer synthesis}

Diacid monomer 7 was synthesized by the condensation reaction of an equimolar amount of TMA and $S$-valine in reflux acetic acid solution (figure 1) (Mallakpour et al 2002). Diamine monomer 4 was synthesized using a twostep process (figure 1). In the first step, aromatic nucleophilic displacement of 3,5-dinitrobenzoylchloride with dopamine hydrochloride in the presence of propylene oxide in DMAc solvent resulted in $\mathrm{N}$-(3,4-dihydroxyphenethyl)-3,5-dinitrobenzamide (3) as a pale yellow solid. In the second step, this dinitro compound was reduced in ethanol in the presence of hydrazine hydrate and a catalytic amount of palladium on the activated carbon at $80^{\circ} \mathrm{C}$, producing yellow crystals of the hydroxylated diamine 4 . The structure of the dinitro 3 and diamine 4 was identified by elemental analysis, FT-IR, ${ }^{1} \mathrm{H}-\mathrm{NMR}$, and ${ }^{13} \mathrm{C}$ NMR spectroscopy (Mallakpour and Zadehnazari 2012c).

\subsection{Polymer synthesis}

Several methods for the synthesis of PAIs have been reported. Some of the reported methods require a prolonged reaction time and the use of toxic solvents. The growing interest during the past two decades in the environmental protection has made both modern, academic and industrial groups develop green chemical processes with maximum yield and minimum cost (Du et al 2011; Sugamoto et al 2011). As part of our programme, which aimed at development of synthetic methodologies (Mallakpour and Rafiee 2011) by eliminating flammable, toxic or carcinogenic organic solvents, we employed a molten ionic salt, TBAB, as a green chemical medium for step-growth polymerization. The rapid use of microwave activation as a nonconventional energy source in organic chemistry also helped us in devising this synthetic route. A synthetic method using molten TBAB and microwave irradiation collectively, was found to be successful and efficient for the synthesis of polymers (Mallakpour and Zadehnazari 2012a,b). Consequently, the monomers (4 and 7) mixtures were irradiated under microwave (optimized condition; $100 \%$ of power level, $120^{\circ} \mathrm{C}$ ) with TBAB in the presence of TPP for $4 \mathrm{~min}$. We observed that the PAI was obtained in $88 \%$ of isolated yield. Thus, we found that molten TBAB salt was a highly polar medium that was likely to be strong microwave absorption. The inherent viscosity of the synthesized PAI was $0.53 \mathrm{dL} / \mathrm{g}$. The resulting polymer showed optical rotation, indicating that the polymer was optically active and 
chirality was introduced into the backbone of the polymer. The optical specific rotation of this polymer was $[\alpha]_{\mathrm{Na}, 589}^{25}=-27.98(0.05 \mathrm{~g}$ in $10 \mathrm{~mL}$ of DMF $)$. The structure of this polymer was confirmed as PAI using FT-IR spectroscopy, ${ }^{1} \mathrm{H}-\mathrm{NMR}$, and elemental analysis techniques (Mallakpour and Zadehnazari 2012c).

\subsection{Preparation of MWCNTs-Val}

$S$-Valine amino acid was explored to react with MWCNTs (figure 2). A condensation reaction occurred between the amino group of amino acid and carboxylic acid group of the MWCNT's surface. Amino acid is cheap and environmentally friendly, so it is a more accommodating electrophilic reagent. Microwave irradiation was used as an important means in our experiment to carry out amino acid-functionalization of MWCNTs. Surface functionality groups and the morphology of MWCNTs were analyzed by FT-IR spectroscopy, XRD, TGA, FESEM and TEM.

\subsection{Composite films preparation}

The dispersion of the MWCNTs-Val in 5, 10, and $15 \mathrm{wt} \%$ solutions of PAI in DMAc was attained by vigorous stirring at a speed of 15,000 rpm for 1 day, using a homogenizer, which was followed by utrasonication process for $1 \mathrm{~h}$ to form a new series of NCs. The reaction pathway for preparing MWCNT-Val/PAI NCs is shown in figure 2. The effective use of CNTs in composite applications depends on the ability to disperse the CNTs uniformly throughout the matrix without reducing their aspect ratio. Due to the van der Waals attraction, CNTs are held together as bundles and ropes. Therefore, they have a very low solubility in solvents and tend to remain as entangled agglomerates. To employ CNTs as an effective reinforcement in polymer composites and ensure proper dispersion and appropriate interfacial adhesion between the CNTs and polymer matrix, several mechanical/ physical methods have been used (Lee et al 2010b; Mallakpour and Zadehnazari 2012a, 2013a). So, in this study, at first, the MWCNTs were functionalized with amino acid. Several researchers have recently investigated the properties of CNT/polymer composites with CNT content from 1 to $15 \mathrm{wt} \%$ and good results have been obtained and reported (Peng et al 2007; Al-Saleh and Sunderaraj 2009; Feng et al 2010). From this point of view, we selected $5-15 \%$ of CNT content in the NCs. The lower level of aggregation in the modified CNTs can be attributed not only to the presence of functional groups such as amino acid groups, but also to their high aspect ratio. This transformation should contribute positively to the good dispersion of CNT in the PAI matrix. Moreover, the introduction of several functional groups into the backbone of aromatic polymer performs hydrogen bonding with modified CNTs and a composite based on hydrogen bond by which PAI chains are tightly attached to the surface of MWCNT-Val can be resulted. Possible interactions between PAI chains and MWCNT-Val are described in figure 3 .

\subsection{Characterization of the MWCNTs and the NCs}

3.5a Structural characterization: FT-IR was used to determine the chemical groups attached to the MWCNTs. Figure 4 shows FT-IR spectra of the carboxylated MWCNT and the MWCNTs-Val. In contrast with MWCNT-COOH, the MWCNT-Val samples provided good evidence for the desired functionalities. The spectrum of a carboxylated MWCNTs/KBr pellet showed a strong, broad absorption band centred at $3433 \mathrm{~cm}^{-1}$, which could be attributed the $\mathrm{O}-\mathrm{H}$ stretching bands of carboxylic acid moieties from the surface of MWCNTs. The small peak around $2923 \mathrm{~cm}^{-1}$ was ascribed to aliphatic $s p^{3} \mathrm{C}-\mathrm{H}$ of MWCNTs (Lee et al 2005). The N-H groups observed on the functionalized samples could indicate that amidation reactions occurred between the amino groups of amino acid and the carboxyl groups on the surfaces of the MWCNTs. The intensities of the bands in the range of $3408-3451 \mathrm{~cm}^{-1}$ and the peak at around $1627 \mathrm{~cm}^{-1}$, which were assigned to the stretching vibration of $\mathrm{O}-\mathrm{H}$ bond and $\mathrm{C}=\mathrm{O}$ of amide bond, respectively, indicated that the amino acid had been successfully attached to the surface of MWCNTs. The peaks at 2923 and $1384 \mathrm{~cm}^{-1}$ were assigned to the stretching and in-plane bending vibrations of the $\mathrm{C}-\mathrm{H}$ bonds of the alkyl group, respectively. The formation of PAI was also confirmed by using FT-IR spectroscopy. Strong absorption bands were observed at $1777 \mathrm{~cm}^{-1}$. This can be related to the asymmetric and symmetric stretching vibrations of the imide carbonyl groups. The bands of $\mathrm{C}-\mathrm{N}$ bond stretching and ring deformation appeared at 1376 and $726 \mathrm{~cm}^{-1}$. Strong bands of absorption characteristics were characteristic of the hydroxyl group and the newly formed amide linkage appeared at around $3392 \mathrm{~cm}^{-1}$. They were assigned to $\mathrm{O}-\mathrm{H}$ and $\mathrm{N}-\mathrm{H}$ stretching vibrations at $1648 \mathrm{~cm}^{-1}$, which can be attributed to amide $\mathrm{C}=\mathrm{O}$ stretching vibration; and at $1547 \mathrm{~cm}^{-1}$, they were due to $\mathrm{N}-\mathrm{H}$ bending vibration. The absorption band at around $3101 \mathrm{~cm}^{-1}$ was attributed to $=\mathrm{CH}$ aromatic linkage. The aliphatic $\mathrm{C}-\mathrm{H}$ stretching peak also appeared at around $2962 \mathrm{~cm}^{-1}$ (Hsiao et al 2011). The presence of CNTs in the polymer matrix showed very few changes in the FT-IR spectrum, presumably due to the low MWCNT composition and the weak vibration signals of MWCNTs. Figure 4 shows the representative FT-IR spectrum of MWCNT-Val/PAI $15 \mathrm{wt} \%$. The structure of neat PAI was also identified by ${ }^{1} \mathrm{H}$-NMR spectroscopy. In the ${ }^{1} \mathrm{H}-\mathrm{NMR}$ spectrum of this polymer, the presence of the $\mathrm{N}-\mathrm{H}$ protons of amide groups at $8.75,10.77$ and $10.84 \mathrm{ppm}$ and $\mathrm{O}-\mathrm{H}$ groups at 


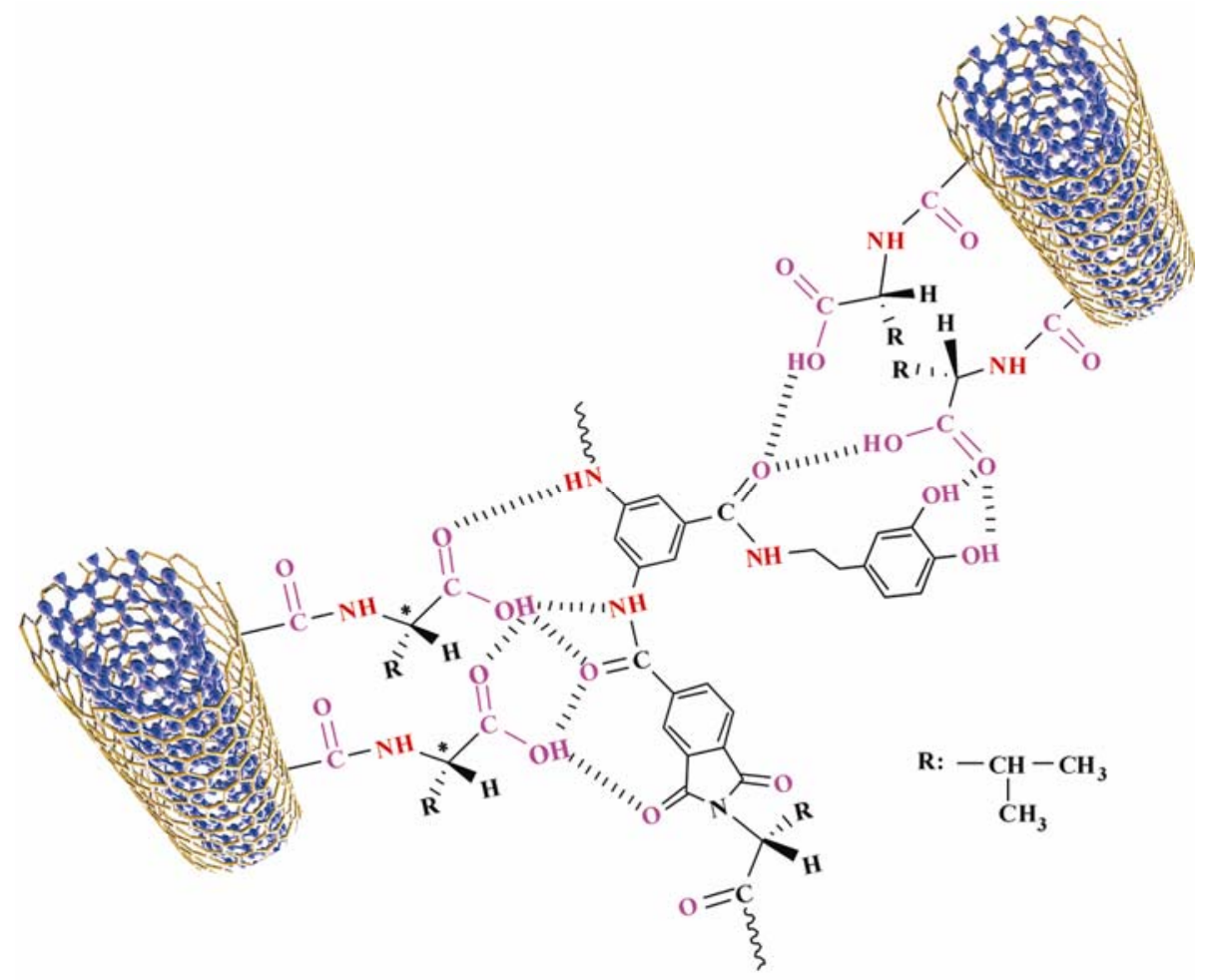

Figure 3. Possible hydrogen bonds between functional groups along a functionalized nanotube and the PAI chains.

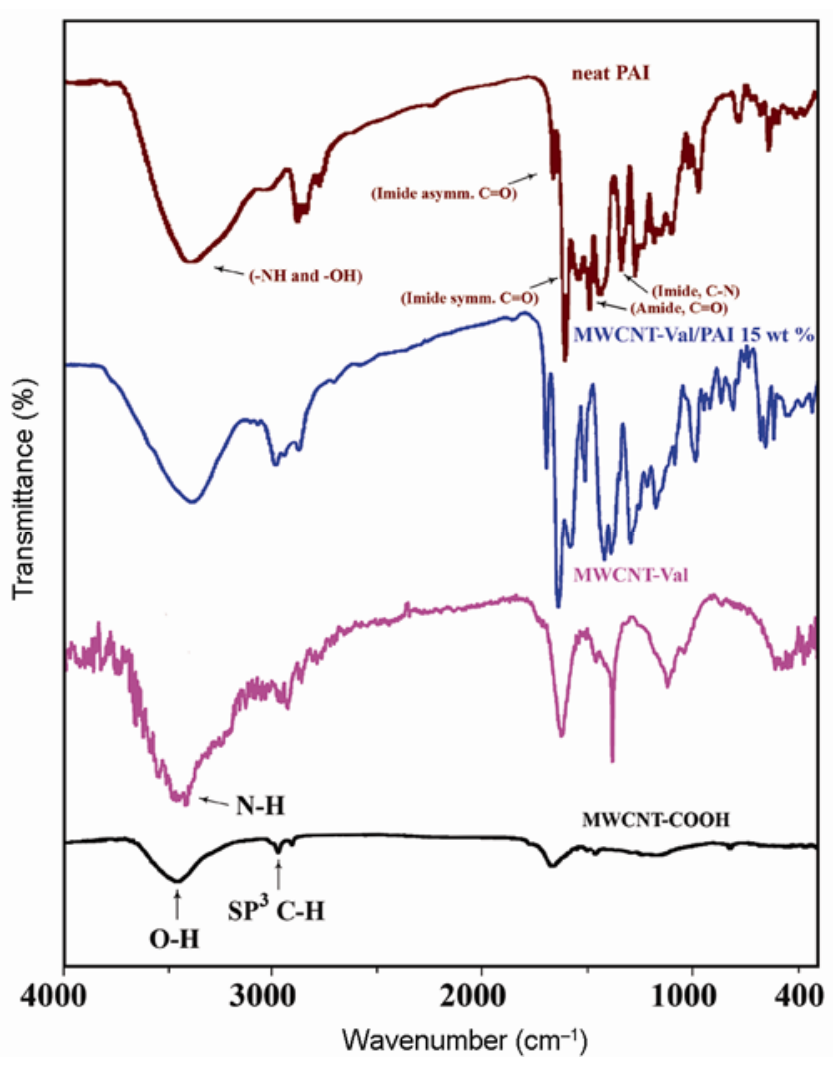

Figure 4. FT-IR spectra of functionalized MWCNTs, PAI and the NC containing $15 \mathrm{wt} \%$ of MWCNT-Val.
10.22 and $10.31 \mathrm{ppm}$ as five singlet peaks indicated the presence of amide groups in the polymer's side chain as well as the main chain and hydroxyl groups in the polymer's side chain. The resonance of aromatic protons appeared in the range of $6 \cdot 47-8.65 \mathrm{ppm}$. Also, the proton of the chiral centre appeared as a doublet at $4.73 \mathrm{ppm}$.

3.5b XRD analysis: The structure of the MWCNTs was examined by XRD. The resultant curves are shown in figure 5. For MWCNTs, two peaks appeared at $2 \theta=26^{\circ}$ and $44^{\circ}$, which are typically associated with diffraction metal impurities $\left(2 \theta=26^{\circ}\right)$ corresponds to the (002) diffraction plane of the impurity graphite, and $\left(2 \theta=44^{\circ}\right)$ to $\alpha$-Fe (110) and/or Ni (111) diffractions (Pérez-Cabero et al 2003). Amino acid-functionalized MWCNTs showed very few changes in the XRD pattern. It could be seen that the XRD pattern is much similar to the carboxylated MWCNTs. Amino acid-modified MWCNTs still had the same cylinder wall structure as raw MWCNTs and interplanner spacing of all samples remained the same. XRD patterns of the MWCNT/PAI composite materials are also presented in figure 5 and they can be compared to the MWCNTs and the pure polymer. For the neat PAI, the weak reflection centred at a $2 \theta$ value around $20^{\circ}$ was characteristic of the amorphous polymer. Composite samples showed XRD patterns similar to the pure polymer when the MWCNT-Val composition was $5 \mathrm{wt} \%$. For the MWCNT-Val content higher than $5 \mathrm{wt} \%$, the 
MWCNT-Val/PAI composites exhibited peaks of PAI and MWCNT-Val, as shown in figure 5. The reflections at $2 \theta=20^{\circ}$ and $26^{\circ}$ were slightly increased when the MWCNT-Val composition was increased to $15 \mathrm{wt} \%$.

3.5c Thermal analysis of the NCs: The thermal stability of the resulting materials was evaluated by TGA under nitrogen atmosphere at a heating rate of $10^{\circ} \mathrm{C} \mathrm{min}^{-1}$, and the corresponding weight loss temperatures of 5 and $10 \%$ ( $T_{5}$ and $T_{10} \%$ ) were all determined from original TGA curves. TGA curves of the functionalized MWCNTs, PAI and the NCs are shown in figure 6 and thermal analysis data from the TGA curves of the samples are summarized in tables 1 and 2. Single-step degradation was observed in all samples. The curve of pristine CNT showed a small mass loss in a temperature range of $0-550{ }^{\circ} \mathrm{C}$. MWCNTVal showed a steady weight loss between 180 and $500{ }^{\circ} \mathrm{C}$, when heated from room temperature to $800{ }^{\circ} \mathrm{C}$ in a nitrogen atmosphere. The weight loss of MWCNT-Val resulted from the decomposition of the functionalized organic moieties attached to the surface of MWCNTs. TGA data of the pristine and the purified MWCNTs suggested that the MWCNTs were able to withstand oxidation temperatures up to $700{ }^{\circ} \mathrm{C}$. This could be due to the incorporation of $-\mathrm{COOH}$ groups in the defective sites and tips. The initial decomposing temperature of the MWCNT-COOH was $550{ }^{\circ} \mathrm{C}$, indicating that the acidtreated CNTs were thermally stable up to this temperature, as shown in table 1 . When MWCNTs were functionalized with amino acid, the weight loss at less than

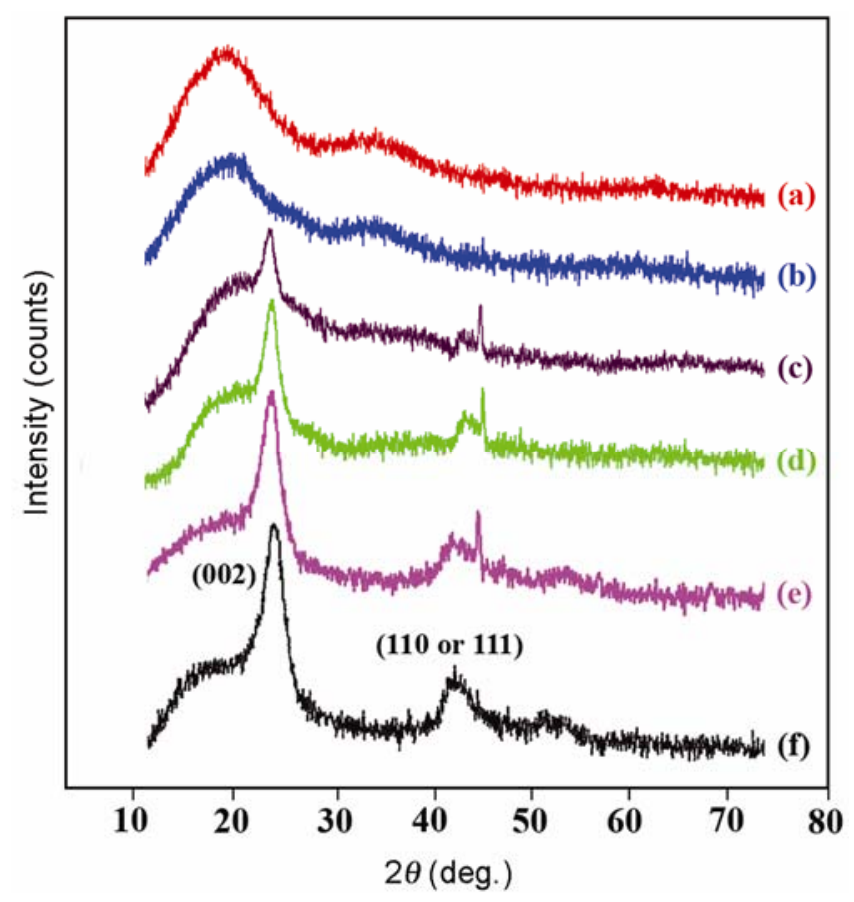

Figure 5. XRD patterns for (a) PAI, composites containing (b) $5 \mathrm{wt} \%$, (c) $10 \mathrm{wt} \%$, (d) $15 \mathrm{wt} \%$ of MWCNT-Val, (e) MWCNT-Val and (f) MWCNT-COOH.
$500{ }^{\circ} \mathrm{C}$ mainly arose from the contribution of amino acid molecules incorporated over MWCNTs. The TGA plot showed that the degradation of specimen MWCNT-Val occurred at $240-600{ }^{\circ} \mathrm{C}$ temperature range. Comparing the amino acid-functionalized MWCNTs with carboxylated MWCNTs, it can be concluded that the thermal stability of MWCNTs-COOH is destroyed upon functionalization with amino acid. The thermal behaviour data for the PAI and the composites are summarized in table 2. The onset of decomposition temperature of the NCs was higher than that of pure PAI, shifting towards higher temperatures as the amount of MWCNT was increased. The $T_{10}$ of the composite with $5 \mathrm{wt} \%$ of MWCNTs-Val exhibits a temperature $53{ }^{\circ} \mathrm{C}$ higher than that of pure PAI. Compared to previous study, in the use of carboxylated MWCNTs (Mallakpour and Zadehnazari 2012a, 2013a), this improvement was not observed. By using carboxylated CNTs, it exhibited a $15^{\circ} \mathrm{C}$ higher than that of pure PAI. The marginal increase in thermal stability of PAI matrix upon incorporation of MWCNTs-Val could be attributed to the higher thermal conductivity of CNTs that facilitated heat

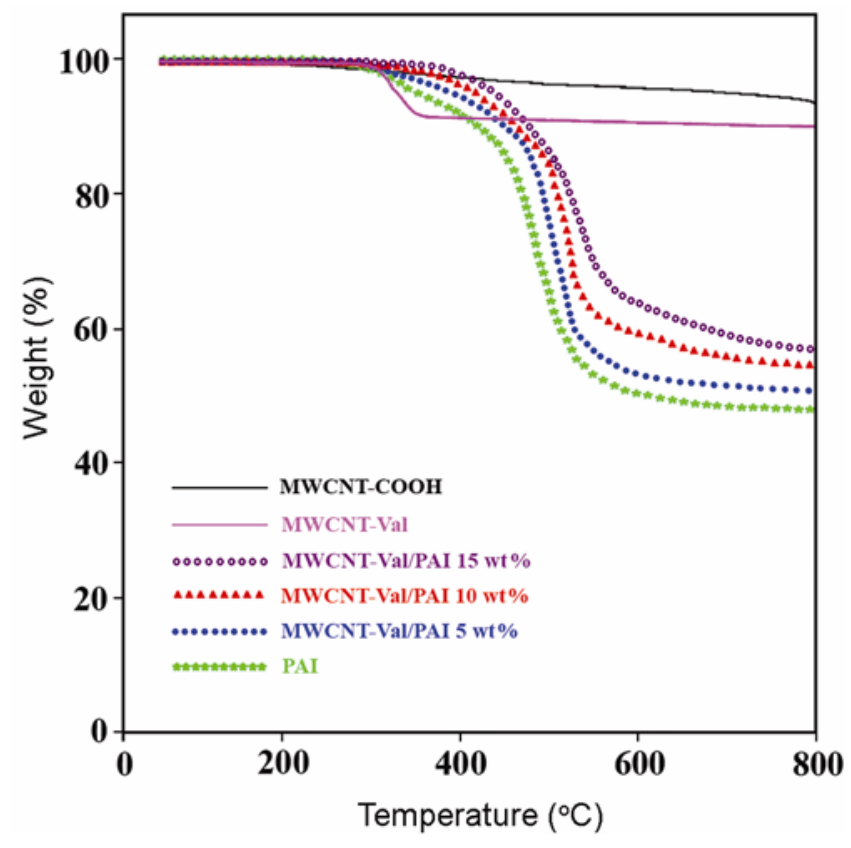

Figure 6. TGA curves for carboxylated and amino acidfunctionalized MWCNTs, neat PAI and the NCs containing 5-15 wt\% of MWCNTs-Val.

Table 1. Thermal stability of CNT samples obtained from TGA thermograms ${ }^{\mathrm{a}}$.

\begin{tabular}{lcc}
\hline Sample & $T_{5}\left({ }^{\circ} \mathrm{C}\right)$ & Weight remaining at $800{ }^{\circ} \mathrm{C}$ \\
\hline MWCNT-COOH & 550 & 90 \\
MWCNT-Val & 270 & 86 \\
\hline
\end{tabular}

${ }^{\mathrm{a}}$ Temperature at which $5 \%$ weight loss was recorded by TGA at a heating rate of $10^{\circ} \mathrm{C} \mathrm{min}-1$ in a nitrogen atmosphere. 
Table 2. Thermal properties of PAI and the composites ${ }^{\mathrm{a}}$.

\begin{tabular}{|c|c|c|c|c|c|}
\hline $\begin{array}{l}\text { MWCNTs-Val } \\
\text { content (\%) }\end{array}$ & $T_{5}{ }^{\mathrm{a}}\left({ }^{\circ} \mathrm{C}\right)$ & $T_{10}{ }^{\mathrm{a}}\left({ }^{\circ} \mathrm{C}\right)$ & CR $(\%)^{b}$ & LOI $(\%)^{\mathrm{c}}$ & $\Delta H_{\text {comb }}(\mathrm{kJ} / \mathrm{g})$ \\
\hline 0 & 332 & 417 & 47 & $36 \cdot 3$ & $22 \cdot 0$ \\
\hline 5 & 385 & 436 & 52 & $38 \cdot 3$ & $20 \cdot 9$ \\
\hline 10 & 420 & 452 & 56 & 39.9 & $20 \cdot 0$ \\
\hline 15 & 436 & 467 & 59 & $41 \cdot 1$ & $19 \cdot 5$ \\
\hline
\end{tabular}

dissipation within the composites, hence preventing the accumulation of heat at certain points for degradation (Huxtable et al 2003). The end temperature of decomposition was also retarded with increasing MWCNT-Val content. The weight percent remaining after major degradation at $800{ }^{\circ} \mathrm{C}$ was higher for composites than for neat PAI. This indicated that MWCNT reduced the degradation of PAI at high temperature as the effect was clearly seen in the curves. Therefore, it could be demonstrated that a small amount of MWCNT acted as effective thermal degradation resistant reinforcement in the PAI matrix, increasing the thermal stability of the MWCNT/PAI NCs.

3.5d Limiting oxygen index-self-extinguishing material: The limiting oxygen index (LOI) is a measure of the percentage of oxygen present to support the combustion of the material. It can be used to evaluate the flameretardancy. Two interesting relationships have been found between the LOI and the parameters of the combustion process: char yield or char residue (CR) and heat of combustion. The percentage of oxygen in the air is around $21 \%$. It is clear that all the materials with an LOI lower than this level will burn easily, while those with a higher LOI will tend not to burn. Theoretically, CR can also be used as a criterion for evaluating LOI of materials.

The CR can be applied as a decisive factor for estimated LOI of polymers according to Van Krevelen (1975) (1)

$$
\mathrm{LOI}=(17 \cdot 5+0 \cdot 4 \mathrm{CR}) / 100 \text {. }
$$

From this equation, a higher CR will improve flame retardance. PAI and composites containing 5, 10 and $15 \mathrm{wt} \%$, had LOI values $36 \cdot 3,38 \cdot 3,39.9$ and $41 \cdot 1$, respectively, which were calculated from their CR. On the basis of the LOI values, such materials can be classified as self-extinguishing materials.

There is also an interesting relationship between the LOI and heat of combustion according to Johnson (1975) (2)

$$
\mathrm{LOI}=8000 / \Delta H_{\mathrm{comb}}
$$

where $\Delta H_{\text {comb }}$ is the specific heat of combustion in $\mathrm{J} / \mathrm{g}$. So, in the case of the obtained PAI and MWCNT-Val/ PAI NCs (5, 10 and $15 \mathrm{wt} \%), \Delta H_{\text {comb }}$ is 22, 20.9, 20 and $19.5 \mathrm{~kJ} / \mathrm{g}$, respectively.

3.5e Morphology studies: In order to observe changes in the morphology of the MWCNTs, FESEM imaging of the samples was carried out and compared with those of the pristine MWCNTs-COOH. A representative image of amino acid-functionalized MWCNTs, along with an image of carboxylated MWCNTs, is shown in figure 7. The FESEM image of the MWCNTs-COOH surface is approximately smooth. After functionalization with amino acid, the surface of MWCNTs becames a rough and debundled structure, as can be seen in figure 7. It can also be seen that the surfaces of MWCNTs were densely functionalized by small size groups. FESEM images of fracture surfaces of neat PAI and composites were also examined to characterize the morphology and dispersity of MWCNTs-Val in the NCs, as displayed in figure 7. The neat PAI copolymer showed a spongy morphology. FESEM observation revealed that the PAI particles were self-organized into nanopatterns. As shown, the average diameter of polymeric particles was about $65 \mathrm{~nm}$ and the shape of them was almost spherical. For MWCNT/PAI NCs, MWCNTs were well dispersed and embedded in the PAI matrix without showing noticeable MWCNT aggregates. In addition, the MWCNT/PAI composites were relatively smooth without exhibiting the pull-out of MWCNTs from the PAI matrix and the boundary between MWCNTs and PAI matrix is not discernible clearly. These results strongly support that due to hydrogen bonding between MWCNT-Val and several functional groups in the PAI structure, the MWCNTs were mixed well with the PAI matrix, eventually leading to the good dispersity and compatibility of MWCNT-Val in the PAI matrix. Figure 8 presents TEM images of the MWCNT-Val. As can be seen, they depict a high surface roughness for the MWCNTs-Val. This surface roughness may imply the partial damage of graphitic carbon, which could have resulted from the severe functionalization and/or oxidation processes (Amiri et al 2011). Although TEM could not distinguish minute functional groups, it 

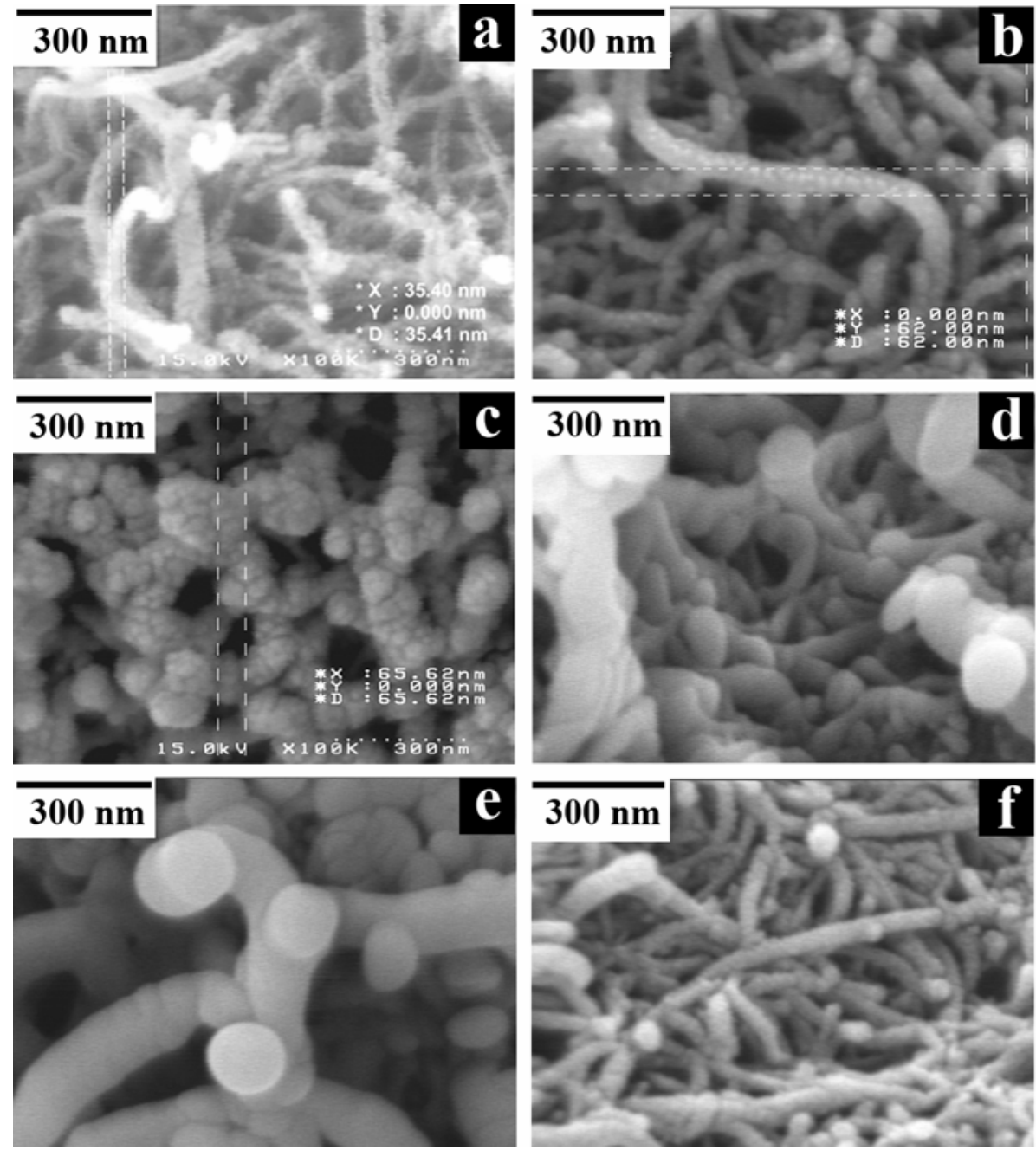

Figure 7. FESEM photograph of samples: (a) MWCNT-COOH, (b) MWCNT-Val, (c) pristine PAI, and NCs containing (d) $5 \mathrm{wt} \%$, (e) $10 \mathrm{wt} \%$ and (f) $15 \mathrm{wt} \%$ MWCNTs-Val.

could represent surface deterioration of the CNTs that occurred as a result of functionalization. As mentioned earlier, the functionalization reaction disrupted the $s p^{2}$ carbon network of graphitic CNTs, so it may be responsible for the roughness of CNTs' surfaces. In fact, since the microwave radiation was harsh enough to produce highly disordered carbon (figure 8), it is likely that it could also damage graphitic MWCNTs (Vázquez and Prato 2009). Furthermore, the formation of helix structures in CNTs confirms the functionalization as distinguished by TEM images. These structures were due to the interaction of the hydrogen bond donor and acceptor (secondary interaction) residues of the amino acids. They had the shape of a folding structure. The helix involves regularly spaced $\mathrm{H}$-bonds between residues along a functionalized nanotube. The amide hydrogen and the carbonyl oxygen of an amide bond are H-bond donors and acceptors, respectively. These interactions created a spatial helical conformation which can be seen in CNTs in some cases. The representative TEM images of the MWCNT/PAI compo- sites are shown in figure 9. In general, the drawbacks related to the homogeneous dispersion of the CNTs in the polymer matrix resulted from intrinsic van der Waals attractions between the individual CNTs in combination with high aspect ratio and large surface area. This made it difficult for the CNTs to disperse in the polymer matrix. The interfacial adhesion between the CNTs and the polymer matrix plays an important role in improving the properties of the polymer composites. As shown in figure 9, the MWCNTs were dispersed well in the composites. This can be explained by the fact that the MWCNT stabilizes their dispersion by good interactions with the PAI matrix, resulting from the increased polarity by the functional groups formed on the surfaces of the MWCNTs as well as good interactions of the carboxyl groups with the carbonyl groups of the PAI matrix. The presence of the functional groups on the surfaces of the MWCNTs resulted in the interfacial interaction between the polymer matrix and the CNTs in the composites. These results strongly support that due to hydrogen bonding between 
MWCNT-Val and carbonyl and hydroxyl groups in the side chains of the PAI, the MWCNTs-Val are wrapped around PAI particles and MWCNTs are also mixed well with the PAI matrix, eventually leading to the good dispersion of MWCNT-Val in the PAI matrix.

3.5f Tensile tests: Figure 10 shows the tensile properties of the MWCNT/PAI composites. The tensile strength and the strain at tensile strength varied depending on the amount of CNTs present (table 3). The physical
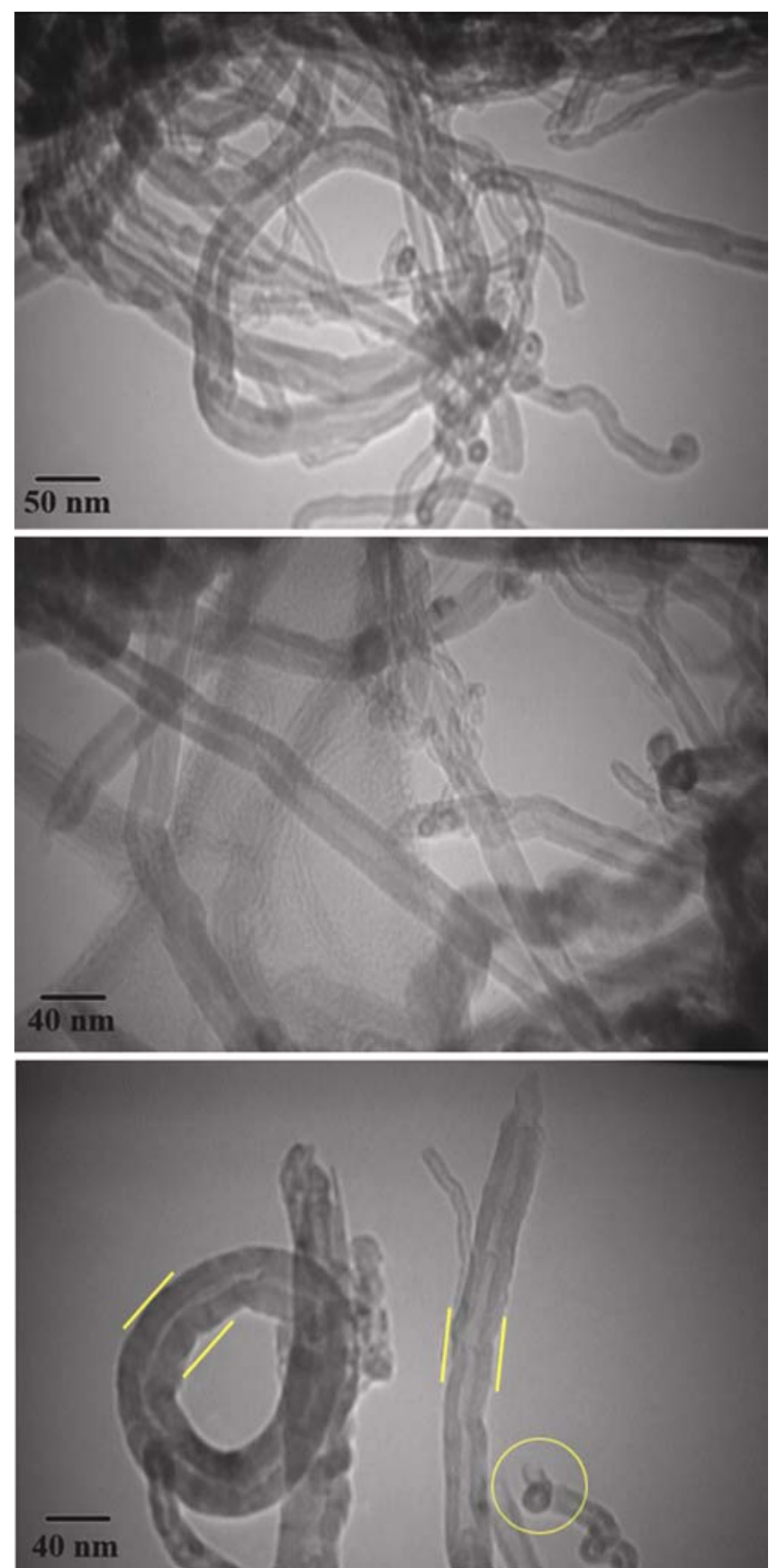

Figure 8. TEM photograph of MWCNT-Val at two different magnifications. interpretation for such an occurrence is that the CNTs were homogeneously oriented in the composite, and the fraction of CNTs oriented in the direction of the tensile force applied was not sufficient to have an impact on the Young's modulus. However, as the sample was stretched, the CNTs are gradually aligned in the direction under tensile testing and, thus, reinforced the material against the fracture. The more CNTs were added to the composite, the bigger was the reinforcement and the higher was the strain. Furthermore, the incorporation of the amino acid
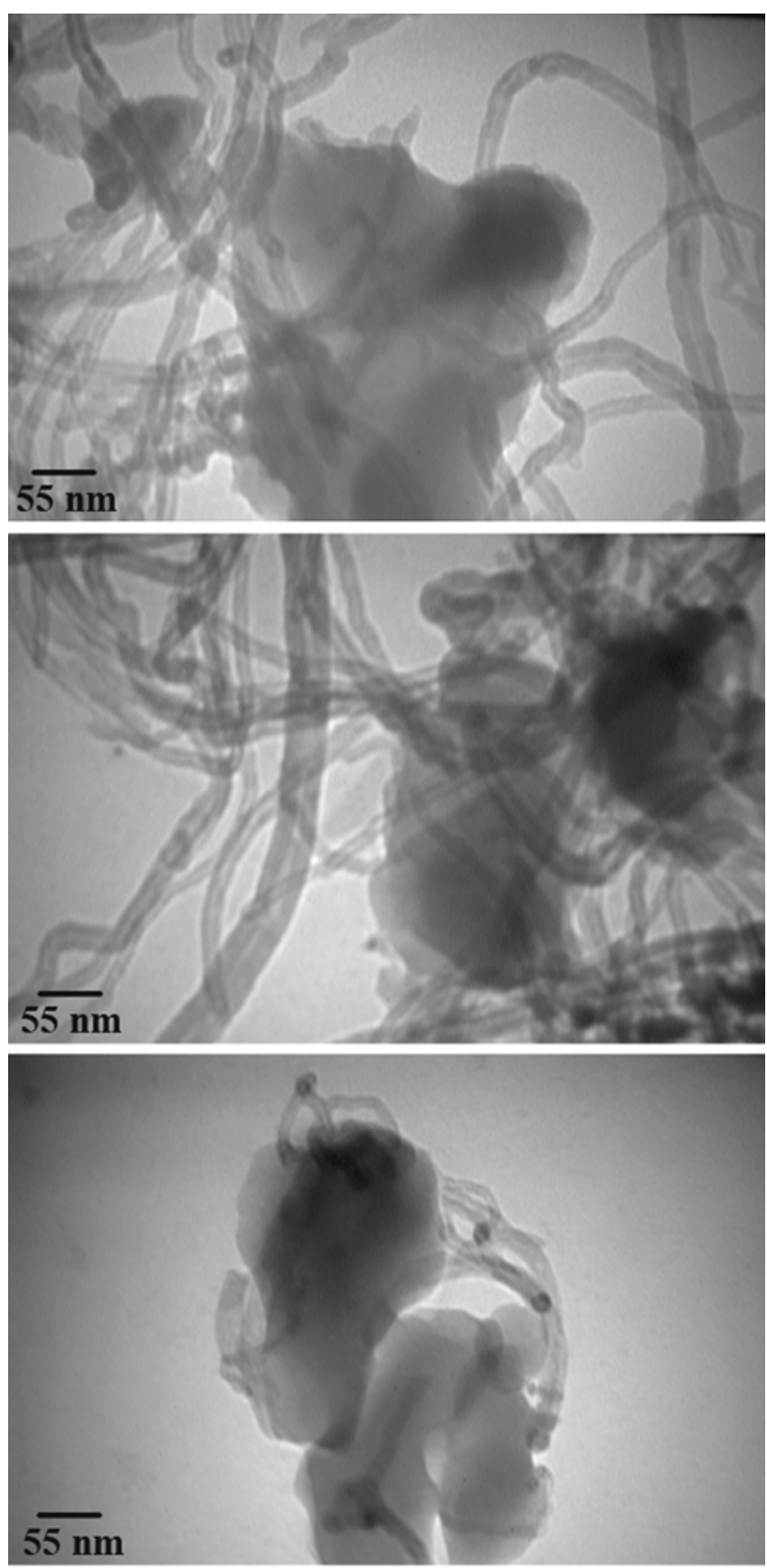

Figure 9. TEM photograph of NC containing $10 \mathrm{wt} \%$ of MWCNT-Val. 
Table 3. Mechanical properties of the composite films with different mass fractions of MWCNT-Val.

\begin{tabular}{lrrrr}
\hline & \multicolumn{4}{c}{ Designation } \\
\cline { 2 - 5 } Properties & \multicolumn{1}{c}{ PAI } & CNT-Val 5\% & \multicolumn{1}{c}{ CNT-Val 10\% } & CNT-Val 15\% \\
\hline$F_{\max }(\mathrm{MPa})^{\mathrm{a}}$ & $72 \cdot 6 \pm 0 \cdot 1$ & $112 \cdot 4 \pm 0 \cdot 3$ & $134 \cdot 3 \pm 0 \cdot 2$ & $145 \cdot 5 \pm 0.2$ \\
$E_{\max }(\%)^{\mathrm{b}}$ & $9 \cdot 2 \pm 0.5$ & $6 \cdot 8 \pm 0 \cdot 4$ & $5 \cdot 5 \pm 0 \cdot 3$ & $4 \cdot 7 \pm 0.4$ \\
$E$-Modulus (GPa) & $1 \cdot 8 \pm 0 \cdot 4$ & $3 \cdot 0 \pm 0 \cdot 2$ & $3 \cdot 7 \pm 0 \cdot 1$ & $4 \cdot 1 \pm 0 \cdot 1$ \\
\hline
\end{tabular}

${ }^{\mathrm{a}} F_{\max }$ : Tensile strength. ${ }^{\mathrm{b}} E_{\max }:$ Elongation at break.

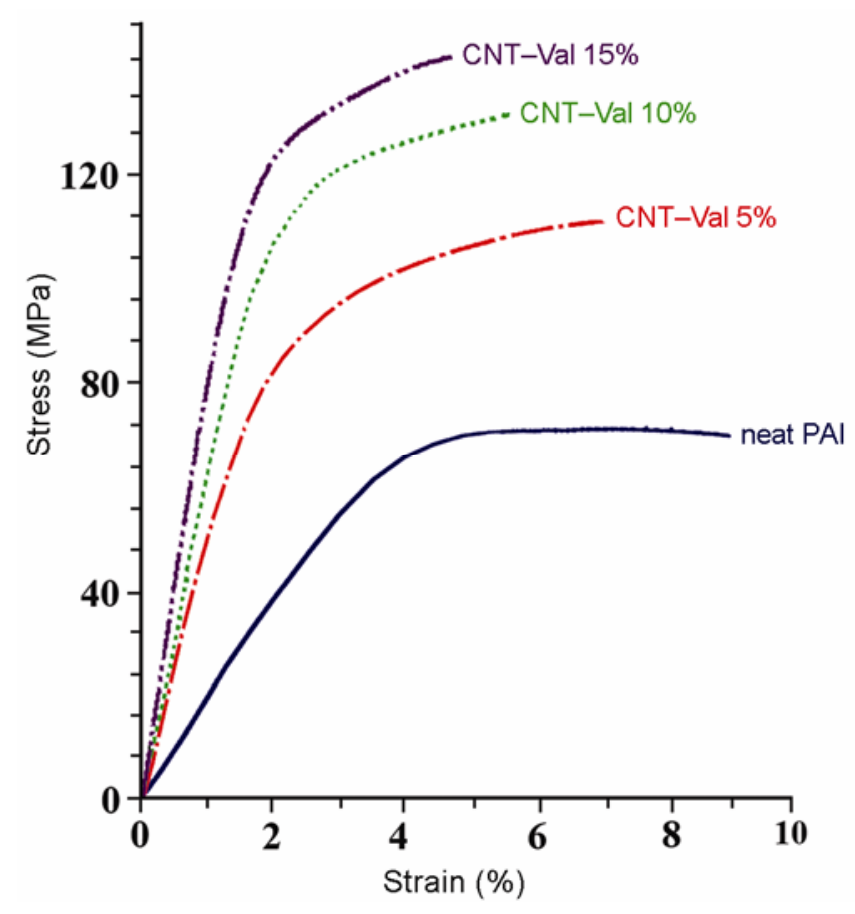

Figure 10. Stress-strain curves of MWCNTs-Val/PAI NCs.

molecules on the surface of MWCNTs and several functional groups into the PAI matrix resulted in the good interfacial adhesion between the MWCNT-Val and the PAI matrix. Therefore, the improvement of the mechanical properties of the MWCNT/PAI NCs could be attributed to the better interfacial interaction between the MWCNTs-Val and the PAI matrix as well as the better dispersion of the MWCNTs-Val in the PAI matrix. This increasing effect of MWCNTs-Val on the tensile strength and tensile modulus of the composites was more significant at low CNT content, when compared with high CNT content. The value in $112.4 \mathrm{MPa}$ for the sample with $5 \mathrm{wt} \%$ MWCNTs loading was $54.8 \%$ higher than that of the pure PAI. Compared to previous study in the use of carboxylated MWCNTs (Mallakpour and Zadehnazari 2012c, 2013a), this improvement was not observed. By using unfunctionalized CNTs, incorporation of 5\% MWCNTs into the PAI film increased its tensile strength to $60.4 \mathrm{MPa}$, which is about $39.6 \%$ higher than that of the pure PAI counterpart. As the loading of MWCNTs-Val became higher (wt $\%=10$ and $15 \%$ ), MWCNTs began to agglomerate to a little extent (figure 7), because of huge surface energy of MWCNTs that caused the stress concentration phenomenon and prevented efficient load transfer to the polymer matrix. The elongation at the break of NC films was decreased with the introduction of MWCNT-Val in the composites, indicating that the composites became somewhat brittle when compared with pure PAI because of the increased stiffness of the composites. Such an embrittlement phenomenon has also been observed in other CNTs reinforced polymer systems (Siochi et al 2004; Ge et al 2005).

\section{Conclusions}

We report an efficient electrophilic addition reaction for the functionalization of MWCNTs using natural amino acid by microwave irradiation, which is easy to scale up with no pollution and low cost. The use of microwave irradiation remarkably increased reaction rates compared to similar syntheses based on conventional heating. The reaction results in the attachment of $S$-valine amino acid to the surface of the nanotubes. Modification with amino acid resulted in significant debundling of the MWCNTs, which allows stable dispersion in common organic solvents such as DMAc. Noteworthy, MWCNTs functionalized with amino acid could provide an economically viable, less-toxic and environmentally friendly alternative, replacing metallic nanoparticles and other nanofillers. The attached amino acid groups are expected to improve the interaction between the modified MWCNTs and polymer chains, and the terminal hydrophilic carboxyl groups can be available for further chemistry and covalent binding with variety of monomer and polymer matrices. The effect of MWCNT-Val loading on the morphology, mechanical and thermal properties of MWCNT-Val/PAI blends has also been investigated. The incorporation of MWCNTs-Val into the amino acidbased PAI matrix has led to the enhancement of both mechanical and thermal properties, especially at low CNT content (5 wt\%). Compared to other CNT/polymer nanocomposites, in this study, it was observed that by incorporating MWCNT-Val, better results were obtained 
in the case of thermal and mechanical properties (Lee et al 2010c; Mallakpour and Zadehnazari 2012c, 2013a). Knowledge of how CNT interacts with biological systems and biomolecules is important to enable the development of new materials that can be used for biomedical devices or tissue regeneration. Further reaction of the MWCNTs with the amino groups is being currently investigated.

\section{Acknowledgements}

This project was supported by the Research Affairs Division of Isfahan University of Technology (IUT), National Elite Foundation (NEF) and Center of Excellency in Sensors and Green Chemistry Research (IUT).

\section{References}

Agarwal A, Rao Bakshi S and Lahiri D 2011 Carbon nanotubes: reinforced metal matrix composites (Boca Raton, FL: CRC Press)

Allen R, Ghita O, Farmer B, Beard M and Evans K 2013 Compos. Sci. Technol. 771

Al-Saleh M H and Sundararaj U 2009 Carbon 471738

Amiri A, Maghrebi M, Baniadam M and Zeinali Heris S 2011 Appl. Surf. Sci. 25710261

Bal S and Samal S S 2007 Bull. Mater. Sci. 30379

Du F Y, Xiao X H and Li J K 2011 Biomed. Chromatogr. 25472

Feng Q P, Yang J P, Fu S Y and Mai Y W 2010 Carbon 48 2057

Friedrich K, Fakirov S and Zhang Z 2005 Polymer composites: from nano-to-macro-scale (New York: Springer)

Ge J J, Zhang D, Li Q, Hou H, Graham M J, Dai L, Harris F W and Cheng S Z 2005 J. Am. Chem. Soc. 1279984

Grady B P 2011 Carbon nanotube-polymer composites: manufacture, properties and applications (Hoboken, New Jersey: John Wiley \& Sons)

Grady B P 2010 Macromol. Rapid. Commun. 31247

Hsiao S H, Guo W, Lee W F, Kung Y C and Lee Y J 2011 Mater. Chem. Phys. 1301086

Huxtable S T, Cahill D G, Shenogin S, Xue L, Ozisik R, Barone P, Usrey M, Strano M S, Siddons G and Shim M 2003 Nat. Mater. 2731

Johnson P R 1974 J. Appl. Polym. Sci. 18491

Laurentia S, Rong W, Sihui T, Lei S and Anthony G F 2013 Desalination 31299

Lee S H, Choi S H, Choi J I, Lee J R and Young J R 2010a Korean J. Chem. Eng. 27658

Lee S H, Choi S H, Kim S Y and Young J R 2010b J. Appl. Polym. Sci. 1173170

Lee S H, Choi S H, Kim S Y, Choi J I, Lee J R and Young J R 2010c Polym. Polym. Compos. 18381
Liaw D J, Wang K L, Huang Y C, Lee K R, Lai J Y and Ha C S 2012 Prog. Polym. Sci. 37907

Ma P C, Siddiqui N A, Marom G and Jang-Kyo K 2010 Composites: Part A 411345

Mallakpour S, Hatami M, Ensafi A A and Karimi-Maleh $\mathrm{H}$ 2011 Chin. Chem. Lett. 22185

Mallakpour S, Hajipour A R and Shahmohammadi M H 2002 Iran. Polym. J. 11425

Mallakpour S and Rafiee Z 2011 Prog. Polym. Sci. 361754

Mallakpour S and Zadehnazari A 2012a Colloid Polym. Sci. (in press) doi: 10.1007/s00396-012-2873-x

Mallakpour S and Zadehnazari A 2012b Soft Mater. 11 494

Mallakpour S and Zadehnazari A 2012c Polym. Plast. Technol. Eng. 511090

Mallakpour S and Zadehnazari A 2013a Carbon 5627

Mallakpour S and Zadehnazari A 2013b J. Polym. Environ. 21 132

Mohan D J and Ahmad A L 2011 J. Macromol. Sci. Phys. 50 1388

Mohanapriya S, Tintula K K, Bhat S D, Pitchumani S and Sridhar P 2012 Bull. Mater. Sci. 35297

Murray T J 2008 Macromol. Mater. Eng. 293350

Ohno K, Tanaka M, Takeda J and Kawazoe Y (eds) 2008 Advances in materials research 9: nano- and micro-materials (New York: Springer)

Park S, Kim K, Kim D M, Kwon W, Choi J and Ree M 2011 ACS Appl. Mater. Interf. 3765

Peng F, Pan F, Sun H, Lu L and Jiang Z 2007 J. Membrane Sci. 30013

Pérez-Cabero M, Rodríguez-Ramos I and Guerrero-Ruíz A 2003 J. Catal. 215305

Rajesh S, Senthilkumar S, Jayalakshmi A, Nirmala M T, Ismail A F and Mohan D 2013 Colloids Surf. A418 92

Scheibe B, Borowiak-Palen E and Kalenczuk R J 2010 Mater. Charact. 61185

Setiawan L, Shi L, Krantz W B and Wang R 2012 J. Membrane Sci. 423-424 73

Siochi E J, Working D C, Park C and Lillehei J H 2004 Composites: Part B 35439

Song Z X, Ding W, Si J H, Yun F, Liu C L, Zhu J and Hou X 2013 Adv. Mater. Res. 651159

Sugamoto K, Matsushita Y and Matsui T 2011 Synth. Commun. 41879

Tang Q Y, Chan Y C and Zhang K 2011 Sens. Actuators B152 99

Thiruvasagam P and Vijayan M 2012 J. Polym. Res. 199845

Van Krevelen D W 1975 Polymer 16615

Vázquez E and Prato M 2009 ACS Nano 33819

Wong M, Paramsothy M, Xu X, Ren Y, Li S and Liao K 2003 Polymer 447757

Zhang M L, Wang X J, Zhang G, Long S R and Yang J 2010 J. Macromol. Sci. Pure Appl. Chem. 47996 